\title{
Review calls for major overhaul of federally funded health organizations
}

\author{
— Cite as: CMAJ 2018 April 16;190:E481-2. doi: 10.1503/cmaj.109-5587
}

Posted on cmajnews.com on Mar. 27, 2018.

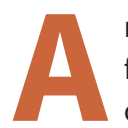
$\mathrm{n}$ external review of federally funded pan-Canadian health organizations found "serious gaps, redundancies, and misalignments that cannot be remedied without retooling." The review calls for a complete overhaul of the suite, including shuttering of three organizations, to refocus on efficiency, innovation, engagement and equity. It also recommends that the government create a "strong data agency to support learning health systems and a strong drug agency to support a national program for prescription drugs."

"We have recommended against the maintenance of the status quo," said
Dr. Danielle Martin, vice-president of medical affairs and health system solutions at Women's College Hospital in Toronto, and a coauthor of the review. "The current suite had too many gaps to be filled with just a little tweaking."

The review looked at eight panCanadian health organizations that account for more than $\$ 300$ million in federal spending each year: the Canadian Centre on Substance Use and Addiction (CCSA), the Canadian Agency for Drugs and Technologies in Health (CADTH), the Canadian Institute for Health Information (CIHI), the Canadian Foundation for Healthcare Improvement (CFHI), Canada Health Info- way (Infoway), the Canadian Patient Safety Institute (CPSI), the Canadian Partnership Against Cancer (CPAC), and the Mental Health Commission of Canada (MHCC).

"Some of these organizations are set up to fail because they're too small to make the impact that they need to make," said Martin. "All of them were built to get us to where we are today, and that's been really helpful, but they do not have what it takes in their current form to get us where we need to go in future."

The review found that few people are clear about what the organizations actually do or who they serve. Most were set up to respond to a pressing public concern, and became symbols of a government's commitment to a cause, "regardless of whether they have fulfilled their original mandate." As a result, the organizations spend "considerable time and effort lobbying for renewed funding," and operate in isolation from each other and health system priorities. Many of their activities duplicate the work of the public sector or other health organizations, and evaluations of their impact lack independence and scientific credibility. The review also found that the organizations were "insufficiently intergenerational and diverse," and "have not seriously undertaken the work of reconciliation" with Indigenous people.

Among recommendations to address these problems, the report proposes phasing out three organizations: the 
Canadian Centre on Substance Use and Addiction, the Canadian Partnership Against Cancer, and the Mental Health Commission of Canada. According to the report, these organizations have "achieved the purpose for which they were established."

The review also recommends that the federal government "recast, re-mandate, and redirect" the remaining five organizations around one of four unifying themes: achieving efficiency, unleashing innovation, fostering engagement, or pursuing equity. As part of that overhaul, Health Canada should clarify the purpose and functions of the organizations, streamline their governance, ensure independent evaluation of their impact, and require the organizations to build "truly pan-Canadian and bilingual teams." Health Canada and Indigenous Services Canada should also initiate a dialogue with Indigenous groups to identify how the organizations could better serve their communities.

The review further calls for the creation of a national drug agency to create and manage a national formulary and oversee drug approvals, assessment, pricing, purchasing and post-market surveillance. The review also recommends that the government merge $\mathrm{CIHI}$ and Infoway into a single data agency. The focus of this agency would shift away from reporting and research to focus instead on the collection, scrubbing, linkage and open provision of health data. It would also "finish Infoway's job of ensuring interoperable digital health systems and a single electronic health record for every patient."

These transformations "would require some additional investment but probably they could also be scoped to the budget that the government is willing to make available," said Martin. "We have not assumed any cost savings across any of these scenarios," she added. "That was not the goal here."

Lauren Vogel, CMAJ 